\title{
Reasons for choice of antibiotic for the empirical treatment of CAP by Canadian infectious disease physicians
}

\author{
Jacob Pendergrast MD, Thomas Marrie MD FRCPC
}

\begin{abstract}
J Pendergast, T Marrie. Reasons for choice of antibiotic for the empirical treatment of CAP by Canadian infectious disease physicians. Can J Infect Dis 1999;10(5):337-345.
\end{abstract}

BACKGROUND: Previous studies have documented substantial variation in physician prescribing practices for the treatment of community-acquired pneumonia. Much of this variation is the result of empirical treatment, in which physicians must choose antibiotics in the absence of culture and sensitivity data.

OBJECTIVE: To explore the factors that influence antibiotic choice for the empirical treatment of community-acquired pneumonia.

MATERIALS AND METHODS: Case-based questionnaires were mailed to all 157 members of the Canadian Infectious Disease Society in June 1996. The questionnaires presented three clinical cases and asked respondents which antibiotics they would most likely prescribe. Half the questionnaires were closed-ended, and half were open-ended. In the former, respondents were asked to explain their antibiotic choice by assigning weights to a list of clinical factors. In the latter, respondents were asked to explain their antibiotic choice by providing a short written answer. Respondents were grouped by the class of antibiotics they selected. These groups were then compared with regards to respondent characteristics (age, years of infectious disease experience, adult versus pediatric practice, country of training, province of practice) and rationale for the treatment chosen. Rationale for drug choice was analyzed statistically for the closed-ended questionnaires and qualitatively for the open-ended questionnaires.

RESULTS: A response rate of $84.6 \%$ was obtained. For the first clinical case, in which the patient was young and had no underlying illness, the majority of respondents chose a macrolide (74.7\%). In the second case, in which the patient was older and had evidence of comorbidity, the most common choice of antibiotic was a penicillin (40.8\%). In the third case, in which the patient had intensive care unit-requiring pneumonia, the most popular choice was combination therapy of a third-generation cephalosporin and a macrolide (43.2\%). There was decreasing consensus regarding the choice of antibiotics as the complexity of the cases increased. There was evidence that prescribing variation could occasionally be attributed to both respondent characteristics and the use of different decision-making strategies.

CONCLUSIONS: Despite the relative homogeneity of the physicians studied, considerable variation in antibiotic choice was observed. In the first case, this variation was based on the issue of whether the patient had a typical or atypical infection. In the second case, the choice of antibiotic was related to the issue of infection by Haemophilus influenzae, although the results of the Gram stain suggested a pneumococcal infection. In the third case, variance appeared to be based more on the respondent's age and province of practice than on any difference in decision-making strategy.

Key Words: Amtibiotic choice; Decision-making; Pneumonia; Treatment

Pour le résumé, voir page suivante

Dalhousie University, Departments of Medicine and Microbiology, Dalhousie University and Victoria General Hospital Site, Queen Elizabeth II Health Sciences Centre, Halifax, Nova Scotia

Correspondence: Dr Thomas Marrie, Room 2F1.20 Walter C Mackenzie Health Science Centre, 8440-112 Street, Edmonton, Alberta T6G 2R7.

Telephone 780-407-6234, fax 780-407-3132,e-mail tom.marrie@ualberta.ca

Received for publication September 29, 1998. Accepted December 18, 1998 


\section{Raisons du choix d'un antibiotique pour le traitement empirique de la pneumonie extra-hospitalière par les médecins canadiens spécialisés en maladies infectieuses}

HISTORIQUE : Des études antérieures ont documenté une variation importante dans les pratiques de prescription des médecins pour le traitement de la pneumonie extra-hospitalière ( $\mathrm{PEH})$. Cette variation est en grande partie le résultat d'un traitement empirique, pour lequel les médecins doivent choisir des antibiotiques en l'absence de cultures ou de données sur la sensibilité.

OBJECTIF : Explorer les facteurs qui influencent le choix d'un antibiotique dans le traitement empirique de la PEH. MATÉRIEL ET MÉTHODES : Des questionnaires basés sur des cas ont été postés en juin 1996 à l'ensemble des 157 membres de la Société canadienne des maladies infectieuses. Les questionnaires présentaient trois cas cliniques et demandaient aux répondants quels antibiotiques ils seraient plus enclins à prescrire dans ces situations. Une moitié des questionnaires étaient à questions fermées, et l'autre moitié à questions ouvertes. Dans le premier type de questionnaire, on a demandé aux répondants d'expliquer leur choix d'antibiotiques en attribuant une importance à une liste de facteurs cliniques. Dans le deuxième type de questionnaire, on a demandé aux répondants d'expliquer leur choix d'antibiotiques en rédigeant une courte réponse. Ensuite, les répondants ont été répartis en groupes selon la classe d'antibiotiques choisie. Ces groupes ont alors été comparés en tenant compte des caractéristiques du répondant (âge, années d'expérience en maladies infectieuses, pratique chez les adultes par rapport à une pratique pédiatrique, pays de formation, province de pratique) et de la raison d'être du traitement choisi. La logique du choix des médicaments a été analysée statistiquement pour ce qui est des questionnaires à réponses fermées et de façon qualitative pour les questionnaires à réponses ouvertes.

RÉSULTATS : On a obtenu un taux de réponse de 84,6\%. Pour le premier cas clinique, dans lequel le patient était jeune, sans maladie sous-jacente, la majorité des répondants a choisi un macrolide (74,7\%). Dans le deuxième cas, dans lequel le patient était plus âgé et présentait une comorbidité, c'est la pénicilline qui a été l'antibiotique le plus souvent choisi $(40,8 \%)$. Dans le troisième cas, où le patient souffrait d'une pneumonie exigeant une hospitalisation dans un service de soins intensifs, les répondants ont privilégié une thérapie combinée d'une céphalosporine de troisième génération et d'un macrolide (43,2\%). Plus les cas devenaient compliqués, plus le consensus concernant le choix des antibiotiques s'amenuisait. Certaines données ont mis en évidence que la variation observée dans la prescription pouvait, de manière occasionnelle, être attribuée à la fois aux caractéristiques propres aux répondants et au recours à des approches différentes dans la prise de décisions.

CONCLUSIONS: Malgré l'homogénéité relative des médecins ayant fait l'objet de l'étude, on a observé une variation importante dans le choix des antibiotiques. Dans le premier cas, cette variation était reliée à la question de savoir si le patient souffrait d'une infection typique ou atypique. Dans le deuxième cas, le choix de l'antibiotique était relié à la question d'une infection à Haemophilus influenzae, même si les résultats de la coloration de Gram favorisaient une infection à pneumocoques. Dans le troisième cas, la variation semblait être basée plus sur l'âge du répondant et sur sa province de pratique que sur des différences dans les approches décisionnelles.

$\mathrm{C}$ ommunity-acquired pneumonia (CAP) is one of the most commonly treated infectious diseases in North America. It is the sixth most common cause of infection-related mortality in the United States, and the cost of treating this disease has been estimated at US $\$ 23$ billion annually (1). More than five million Americans are affected each year, resulting in an estimated one million hospitalizations. Despite continued efforts by the medical profession, pneumonia remains a difficult disease to treat, largely because both the microorganisms that cause it and the demographic profile of the population in which it occurs continue to change and evolve (2). Up to the 1930s, almost all cases of pneumonia were caused by Streptococcus pneumoniae; today, however, almost one-half of the patients hospitalized for CAP never have an etiology of the disease determined (3-17).

In scases where etiology cannot be determined, the treatment of CAP must, by necessity, be empirical (8). There are over 100 different generic antibiotics available for treating CAP, in the penicillin, cephalosporin, macrolide, tetracycline, quinolone, antimetabolite and aminoglycoside classes, with costs ranging from less than $\$ 1$ to over $\$ 100 /$ dose. With a therapeutic armamentarium so large, it is not surprising that there is substantial variation among countries (9-11), institutions $(12-14)$ and physicians $(15,16)$ in the treatment of CAP. Partly in response to this variation, guidelines for the initial empirical treatment of CAP have been formulated (17-20).
The present study was designed to explore the variance in prescribing patterns for CAP among Canadian infectious disease specialists and to gain an understanding of the causes of this variance.

\section{MATERIALS AND METHODS}

Three cases were developed from actual cases of CAP. The cases were designed in such a way as to fall into the three categories of patient recognized by the Canadian Community Acquired Pneumonia Consensus Conference Group (21). The cases were worded as follows.

Case 1: "You have just admitted a 17-year-old male to hospital with fever, nonproductive cough and right middle lobe alveolar opacity on chest radiograph. No sputum is available for culture. What antibiotic(s) would you prescribe?"

Case 2: "A 66-year-old male, 40 pack-year smoker presents with fever and chills of two days' duration. He has a cough that is productive of purulent sputum, which on Gram stain shows many white blood cells and Gram-positive diplococci. What is the antibiotic(s) of choice?"

Case 3: "A 45-year-old previously healthy female was brought to the emergency room by friends because of fever, cough and progressive shortness 
of breath over a four-day period. Her cough is nonproductive, and on chest $\mathrm{x}$-ray she has bilateral lobar pneumonia. $\mathrm{Her} \mathrm{PO}_{2}$ [partial pressure of oxygen] is $45 \mathrm{mmHg}$ while breathing room air, pulse rate is 120 beats/min, respiratory rate 32 breaths/min, and temperature of $39.5^{\circ} \mathrm{C}$. Shortly after admission, her blood pressure dropped to $90 / 60 \mathrm{mmHg}$ from $110 / 70 \mathrm{mmHg}$. You admit her to the intensive care unit. Following appropriate cultures, which antibiotic(s) would you begin therapy with?"

Cases 1, 2 and 3 were then incorporated into two questionnaires. In questionnaire 1 (closed-ended), respondents were asked to use Likert scales to assign a value of 1 to 5 to a list of clinical factors, which, on the basis of previous studies and personal experience, were presumed to be important in the choice of antibiotic for CAP. These clinical factors were 'patient age', 'severity of illness', 'Gram stain', 'immunocompetent', 'immunocompromised' and 'other'. Questionnaire 2 (open-ended) asked the respondents to provide a written explanation for their choice of antibiotic therapy for each case. For both questionnaires, the respondent was asked to provide the following personal information: age, years of experience as an infectious disease specialist, whether they were trained in Canada, their current province of practice, and whether their practice was predominantly adult or paediatric.

The questionnaires were mailed to 157 members of the Canadian Infectious Disease Society during June 1996. Physicians who were listed on the left-hand pages of the Canadian Infectious Disease Society directory were mailed the openended questionnaire, and those listed on the right-side pages were mailed the closed-ended questionnaires.

Data analysis: Antibiotics selected by survey respondents were classified according to chemical structure. Antibiotic classes were defined only after survey responses had been reviewed.

Combination therapy was defined as more than one antibiotic linked by an 'and' modifier. Antibiotics included by a "+/-" modifier were not included in analysis. For example, both "erythomycin +/- rifampin" and "erythromycin and add TMP/SMX if travel history significant" were shortened to "erythromycin".

A therapeutic category was defined as either an antibiotic class or combination of antibiotic classes that was chosen frequently by survey respondents. Therapeutic categories were defined only after survey responses had been reviewed.

For both questionnaires, mean age and years of infectious disease experience were compared between different therapeutic classes using a Kruskall-Wallis one-way ANOVA. Correlations between country of infectious disease training (Canada versus abroad), type of practice (adult versus paediatric) and province of practice in Canada versus the therapeutic class of antibiotic(s) chosen was tested using ${ }^{2}$ tests and EPI Info version 6, Atlanta, Georgia (22).

Closed-ended questionnaire: Each case on the closed-ended questionnaires was accompanied by a list of six clinical factors
TABLE 1

Characteristics of the respondents to survey on choice of antibiotic treatments $(n=106)$

\begin{tabular}{|c|c|c|c|c|}
\hline \multirow[b]{2}{*}{ Characteristic } & \multicolumn{2}{|c|}{$\begin{array}{l}\text { Open-ended } \\
\quad(n=58)\end{array}$} & \multicolumn{2}{|c|}{$\begin{array}{c}\text { Closed-ended } \\
\quad(n=48)\end{array}$} \\
\hline & Mean & SD & Mean & SD \\
\hline Age* & 43.7 & 7.2 & 43.9 & 7.7 \\
\hline Years of practice ${ }^{\dagger}$ & 12.5 & 7.3 & 11.1 & 6.0 \\
\hline \multicolumn{5}{|c|}{ Infectious disease training, n (\%) } \\
\hline In Canada & \multicolumn{2}{|c|}{$35(60.3)$} & \multicolumn{2}{|c|}{$28(58.3)$} \\
\hline Not in Canada & \multicolumn{2}{|c|}{$23(39.7)$} & \multicolumn{2}{|c|}{$20(41.7)$} \\
\hline \multicolumn{5}{|l|}{ Type of practice, n (\%) } \\
\hline Mostly adult & \multicolumn{2}{|c|}{$47(81.0)$} & \multicolumn{2}{|c|}{$41(85.4)$} \\
\hline Mostly paediatric & \multicolumn{2}{|c|}{$8(13.8)$} & \multicolumn{2}{|c|}{$6(12.5)$} \\
\hline Both & \multicolumn{2}{|c|}{$3(5.2)$} & \multicolumn{2}{|c|}{$1(2.1)$} \\
\hline \multicolumn{5}{|l|}{ Place of practice, n (\%) } \\
\hline British Columbia & \multicolumn{2}{|c|}{$4(6.9)$} & \multicolumn{2}{|c|}{$4(8.3)$} \\
\hline Alberta & \multicolumn{2}{|c|}{$4(6.9)$} & \multicolumn{2}{|c|}{$10(20.8)$} \\
\hline Saskatchewan & \multicolumn{2}{|c|}{$1(1.7)$} & \multicolumn{2}{|c|}{$0(0.0)$} \\
\hline Manitoba & \multicolumn{2}{|c|}{$3(5.2)$} & \multicolumn{2}{|c|}{$4(8.3)$} \\
\hline Ontario & \multicolumn{2}{|c|}{$23(39.7)$} & \multicolumn{2}{|c|}{$10(20.8)$} \\
\hline Quebec & \multicolumn{2}{|c|}{$18(31.0)$} & \multicolumn{2}{|c|}{$13(27.1)$} \\
\hline New Brunswick & \multicolumn{2}{|c|}{$0(0.0)$} & \multicolumn{2}{|c|}{$2(4.2)$} \\
\hline Nova Scotia & \multicolumn{2}{|c|}{$3(5.2)$} & \multicolumn{2}{|c|}{$3(6.3)$} \\
\hline Prince Edward Island & \multicolumn{2}{|c|}{$0(0.0)$} & \multicolumn{2}{|c|}{$1(2.1)$} \\
\hline Newfoundland & \multicolumn{2}{|c|}{$0(0.0)$} & & \\
\hline United States & & & & \\
\hline Total & 58( & .0) & 48( & \\
\hline
\end{tabular}

*Age was not provided by two respondents; ${ }^{\dagger}$ Excluding six respondents who did not provide years of experience, or responded with "resident" or "fellow"

with accompanying Likert scales. Respondents were asked to assign weights to the Likert scales to indicate the importance of each particular clinical factor in their choice of antibiotic. If respondents left a Likert scale blank, assigned it a value of 0 or a non-numeric value, a value of 1 (lowest value) was assigned. If a respondent left all six Likert scales blank however, a null value was assigned to each scale.

It was hypothesized that variation in choice of antibiotics for each case correlated with varying levels of importance that respondents attached to the six clinical factors. For example, it was predicted that respondents who chose penicillin for case 2 would weigh the importance of the Gram stain result higher than respondents who chose other antibiotics. This hypothesis was tested by conducting a two-factor repeated measures ANOVA for each of the three cases, looking for significant interaction between choice of antibiotic and the weights assigned to the six clinical factors. Significant interaction in this case suggests that the variance in weights assigned to the Likert scales was influenced by the respondent's choice of antibiotic.

open-ended questionnaire: By using terminology developed by Hepler et al (22), an expressed rationale was defined as the reason provided by a respondent for why he or she had chosen a stated antibiotic therapy. Each expressed rationale was analyzed qualitatively by one of the authors for rationale themes, which were defined as an inference about the issue involved in a group of expressed rationales (23). An understanding of the issues involved was gained by consulting review articles on CAP 
TABLE 2

Mean corrected weight assigned to Likert scales of closed-ended questionnaires for a survey of Canadian infectious disease specialists

\begin{tabular}{llc}
\hline & Criterion & Mean \\
\hline Case 1 & Normal immunity & 4.14 \\
& Severity of illness & 4.07 \\
& Patient age & 3.86 \\
& Immunosuppression & 2.49 \\
& Gram stain & 1.93 \\
Case 2 & Other & 1.25 \\
& Gram stain & 4.11 \\
& Severity of illness & 3.61 \\
& Patient age & 3.43 \\
& Normal immunity & 3.04 \\
& Immunosuppression & 2.58 \\
& Other & 1.30 \\
& Severity of illness & 4.76 \\
& Normal immunity & 3.29 \\
& Patient age & 2.72 \\
& Immunosuppression & 2.18 \\
& Gram stain & 1.66 \\
& Other & 1.15 \\
\hline
\end{tabular}

$(1,25)$ by conducting interviews with hospital physicians, and by reviewing what respondents to the closed-ended questionnaire had entered under the 'other' decision-making criterion.

\section{RESULTS}

A total of 157 questionnaires were mailed to members of the Canadian Infectious Disease Society during June 1996. Twenty questionnaires could not be delivered due to change of address. Of the remaining 137, 106 (48 closed-ended, 58 open-ended) were returned ( $77 \%)$. Respondents practising in the United States were excluded, leaving 103 questionnaires for analysis. The characteristics of these respondents are summarized in Table 1. Due to a collating error, four of the respondents to the closed-ended questionnaire were unable to answer case 1 . Another respondent to the closed-ended questionnaire did not answer case 3. Two respondents to the open-ended questionnaire did not answer cases 2 or 3. Overall, respondents to the two surveys did not differ significantly in age, years of experience, country of training or type of practice (eg, adult versus paediatric). Because the large majority of respondents to both questionnaires had adult practices (82.5\%), practice type was not included in subsequent statisti$\mathrm{cal}$ analysis. Most of the returned questionnaires were from Ontario or Quebec, with slightly greater representation from other provinces among respondents to the closed-ended questionnaires.

The majority of antibiotics selected by survey respondents were classified as either macrolide, penicillin (including extended penicillins such as ampicillin and amoxicillin), or first, second or third generation cephalosporin. All other antibiotics were classified as 'other'.

If a respondent listed more than one antibiotic class via an
TABLE 3

Rationale themes identified in open-ended questionnaires for a survey of Canadian infectious disease specialists

\begin{tabular}{|c|c|c|}
\hline & Rationale theme & Frequency \\
\hline \multirow[t]{15}{*}{ Case 1} & Could be either typical or atypical & 27 \\
\hline & Probably atypical & 16 \\
\hline & Patient seriously ill & 8 \\
\hline & Probably typical & 6 \\
\hline & Patient not seriously ill & 6 \\
\hline & Economic consideration & 5 \\
\hline & Patient age & 5 \\
\hline & Chest x-ray & 4 \\
\hline & Resistance a concern & 4 \\
\hline & Clinical examination & 3 \\
\hline & Resistance not a concern & 3 \\
\hline & "Broad coverage" & 2 \\
\hline & Total number of rationale themes & 89 \\
\hline & Number of respondents & 56 \\
\hline & $\begin{array}{l}\text { Average number of themes per expressed } \\
\text { rationale }\end{array}$ & 1.59 \\
\hline \multirow[t]{14}{*}{ Case 2} & Probably Streptococcus pneumoniae & 34 \\
\hline & Resistance not a concern & 14 \\
\hline & Rely on Gram stain & 9 \\
\hline & Resistance a concern & 8 \\
\hline & Patient history & 7 \\
\hline & Assume underlying disease & 6 \\
\hline & $\begin{array}{l}\text { Could be either } S \text { pneumoniae or } \\
\text { Gram-negative bacteria }\end{array}$ & 6 \\
\hline & Do not rely on Gram stain & 4 \\
\hline & Probably Gram-negative bacteria & 3 \\
\hline & Better compliance & 2 \\
\hline & Economic consideration & 2 \\
\hline & Total number of rationale themes & 95 \\
\hline & Number of respondents & 54 \\
\hline & $\begin{array}{l}\text { Average number of themes per expressed } \\
\text { rationale }\end{array}$ & 1.76 \\
\hline \multirow[t]{15}{*}{ Case 3} & Want to cover for Gram-positive bacteria & 35 \\
\hline & Want to cover for atypicals & 35 \\
\hline & Patient seriously ill & 31 \\
\hline & Want to cover for Gram-negative bacteria & 25 \\
\hline & "Broad coverage" & 16 \\
\hline & Want to cover for influenza & 8 \\
\hline & Pseudomonas unlikely & 6 \\
\hline & Chest x-ray & 4 \\
\hline & Resistance a concern & 3 \\
\hline & Follow guidelines & 3 \\
\hline & Want to cover for anaerobes & 3 \\
\hline & Patient history & 3 \\
\hline & Total number of rationale themes & 172 \\
\hline & Number of respondents & 54 \\
\hline & $\begin{array}{l}\text { Average number of themes per expressed } \\
\text { rationale }\end{array}$ & 3.26 \\
\hline
\end{tabular}

'either/or' modifer (for example, "cefuroxime or penicillin"), the respondent's answer was categorized as 'other'. Any antibiotic class or combination therapy that did not fall under the identified defined therapeutic categories was categorized as 'other'. Overall, the most common therapeutic category chosen for case 1 was a macrolide; for case 2 , penicillin; for case 3, combination therapy of a third generation cephalosporin and a macrolide. 
TABLE 4

Three most commonly occurring rationale themes in case 1 (open-ended questionnaires), by therapeutic category

\begin{tabular}{llc}
\hline Therapeutic category & Rationale theme & Frequency \\
\hline Macrolide $(\mathrm{n}=39)$ & $\begin{array}{l}\text { Could be either typical } \\
\text { or atypical } \\
\text { Probably atypical }\end{array}$ & 16 \\
& $\begin{array}{l}\text { Economic consideration } \\
\text { Patient age }\end{array}$ & 5 \\
& Could be either typical & 5 \\
Macrolide and other & or atypical & \\
$(\mathrm{n}=9)$ & Patient seriously ill & 5 \\
Resistance a concern & 3 \\
Other $(\mathrm{n}=8)$ & Probably typical & 3 \\
& Chest x-ray & 2 \\
Could be either typical & 2 \\
or atypical & Patient not seriously ill & 2 \\
\hline
\end{tabular}

The mean corrected weights assigned to the Likert scales for each case of the closed-ended questionnaires are shown in Table 2 . The clinical factor most heavily weighted by respondents for case 1 was 'normal immunity'. For case 2, the most heavily weighted factor was 'Gram stain', while for case 3 it was 'severity of illness'. The rationale themes identified in each case for the open-ended questionnaires are listed in Table 3. Because there was usually more than one rationale theme found in each expressed rationale, the total number of rationale themes enumerated was larger than the number of open-ended questionnaires returned. No rationale themes could be identified for two of the expressed rationales for case 1 , five of the expressed rationales for case 2, and two of the expressed rationales for case 3 .

Case 1 - 17 year-old male no comorbidity and nonsevere clinical presentation: For this case, $74.7 \%$ of respondents chose a macrolide, $13.1 \%$ chose a macrolide in combination with another antibiotic and $12 \%$ chose an antibiotic therapy that did fall into any particular class. Respondents who chose a macrolide did not differ significantly in age, years of experience or location of infectious disease training from respondents who chose a different therapeutic category. There was an insufficient sample size to test for prescribing differences by location of practice.

On the closed-ended questionnaires, two-way ANOVA found no significant interaction between therapeutic category and the corrected weights assigned to the Likert scales for this case $(\mathrm{P}=0.4168)$. Qualitative analysis of the open-ended questionnaires suggested that respondents who chose a single macrolide as the treatment tended to be more confident that the pathogen was 'atypical' (eg, Mycoplasma pneumoniae) than respondents whose choice of antibiotics was categorized as 'other'. Respondents who chose a macrolide in combination with another antibiotic (categorized as 'macrolide and other') were more concerned with the presumed severity of the patient's illness than were other respondents (Table 4).
TABLE 5

Mean corrected weights assigned to Likert scales of case 2 (closed-ended questionnaires) by therapeutic category

\begin{tabular}{llc}
\hline Therapeutic category & Criterion & Mean weight \\
\hline Penicillin $(\mathrm{n}=22)$ & Gram stain & 4.64 \\
& Other & 1.32 \\
& Severity of illness & 3.50 \\
& Normal immunity & 3.23 \\
& Patient age & 3.23 \\
& Immunosuppression & 2.27 \\
2nd generation & Severity of illness & 3.77 \\
cephalosporin $(\mathrm{n}=14)$ & Gram stain & 3.62 \\
& Patient age & 3.54 \\
& Immunosuppression & 3.15 \\
& Normal immunity & 3.15 \\
& Other & 1.23 \\
Other $(\mathrm{n}=11)$ & Severity of illness & 3.78 \\
& Patient age & 3.67 \\
& Gram stain & 3.44 \\
& Immunosuppression & 3.15 \\
& Normal immunity & 2.67 \\
& Other & 1.44 \\
\hline
\end{tabular}

Interaction between therapeutic category and decision-making criteria $P=0.0631$

TABLE 6

Three most commonly occurring rationale themes in case 2 (open-ended questionnaires) by therapeutic category

\begin{tabular}{llc}
\hline $\begin{array}{l}\text { Therapeutic } \\
\text { category }\end{array}$ & Rationale theme & Frequency \\
\hline Penicillin $(\mathrm{n}=20)$ & $\begin{array}{l}\text { Probably Streptococcus } \\
\text { pneumonia } \\
\text { Resistance not a concern }\end{array}$ & 19 \\
& $\begin{array}{l}\text { Rely on Gram stain } \\
\text { Second generation } \\
\text { cephalosporin } \\
(\mathrm{n}=12)\end{array}$ & $\begin{array}{l}\text { Could be either S pneumonia } \\
\text { or Gram negative bacteria }\end{array}$ \\
& Probably S pneumonia & 4 \\
& Assume underlying disease & 2 \\
Other $(\mathrm{n}=22)$ & Resistance not a concern & 2 \\
& Probably S pneumonia & 11 \\
& Resistance a concern & 5 \\
& Assume underlying disease & 3 \\
& Do not rely on Gram stain & 3 \\
& Patient history & 3 \\
& Resistance not a concern & 3 \\
\hline
\end{tabular}

Case 2 - 66-year-old male with comorbidity and nonsevere clinical presentation: For case $2,40.8 \%$ of respondents chose a penicillin, $25.2 \%$ chose a second generation cephalosporin, and $34 \%$ chose an antibiotic therapy that did not fall into any particular class. Respondents who chose a penicillin tended to be older than other respondents, with a correlation approaching significance $(\mathrm{P}=0.13)$. There was no correlation between antibiotic choice and years of infectious disease experience, country of infectious disease training or location of practice.

of the closed-ended questionnaires, two-way ANOVA 
TABLE 7

Relationship between choice of antibiotics for case 3 and respondent age and location of practice

\begin{tabular}{lcccc}
\hline & $\begin{array}{c}\text { Second generation } \\
\text { cephalosporin and } \\
\text { macrolide }\end{array}$ & $\begin{array}{c}\text { Third generation } \\
\text { cephalosporin and macrolide }\end{array}$ & $\begin{array}{c}\text { Third generation cephalosporin, } \\
\text { macrolide and other }\end{array}$ & Other \\
\hline Mean age & 46.2 & 41.3 & 44.8 & 45.4 \\
Location of practice, number (\%) & $5(26.3)$ & $16(35.6)$ & & 0.05 \\
Western provinces & $11(57.9)$ & $10(22.2)$ & $5(38.5)$ & $4(17.4)$ \\
Ontario & $1(5.3)$ & $14(31.1)$ & $6(46.2)$ & $6(26.1)$ \\
Quebec & $2(10.5)$ & $5(11.1)$ & $2(15.4)$ & $12(52.2)$ \\
Atlantic provinces & & & $0(0.0)$ & $1(4.3)$ \\
\hline
\end{tabular}

TABLE 8

Three most commonly occurring rationale themes in case 3 (open-ended questionnaires) by therapeutic category

\begin{tabular}{|c|c|c|}
\hline Therapeutic category & Rationale theme & Frequency \\
\hline \multirow{3}{*}{$\begin{array}{l}\text { Second generation } \\
\text { cephalosporin and } \\
\text { macrolide }(n=9)\end{array}$} & Want to cover for atypicals & 7 \\
\hline & $\begin{array}{l}\text { Want to cover for } \\
\text { Gram-positive bacteria }\end{array}$ & 7 \\
\hline & Patient seriously ill & 4 \\
\hline \multirow{3}{*}{$\begin{array}{l}\text { Third generation } \\
\text { cephalosporin and } \\
\text { macrolide }(n=24)\end{array}$} & Want to cover for atypicals & 16 \\
\hline & $\begin{array}{l}\text { Want to cover for } \\
\text { Gram-positive bacteria }\end{array}$ & 14 \\
\hline & Patient seriously ill & 13 \\
\hline \multirow{6}{*}{$\begin{array}{l}\text { Third generation } \\
\text { cephalosporin, } \\
\text { macrolide and other } \\
(n=8)\end{array}$} & $\begin{array}{l}\text { Probably Streptococcus } \\
\text { pneumonia }\end{array}$ & 11 \\
\hline & Resistance a concern & 5 \\
\hline & Assume underlying disease & 3 \\
\hline & Do not rely on Gram stain & 3 \\
\hline & Patient history & 3 \\
\hline & Resistance not a concern & 3 \\
\hline \multirow[t]{3}{*}{ Other $(n=13)$} & $\begin{array}{l}\text { Want to cover for } \\
\text { Gram-negative bacteria }\end{array}$ & 9 \\
\hline & Patient seriously ill & 9 \\
\hline & $\begin{array}{l}\text { Want to cover for } \\
\text { Gram-positive bacteria }\end{array}$ & 7 \\
\hline
\end{tabular}

found an interaction approaching significance between therapeutic category and the weights assigned to the Likert scale for this case ( $\mathrm{P}=0.0631$, Table 5). Qualitative analysis of the open-ended questionnaires suggested that respondents who chose a penicillin were more confident that the patient had a pneumococcal infection than respondents who chose a second generation cephalosporin, who were more hesitant to rule out a Gram-negative infection (for example, Haemophilus influen$z a e)$. Respondents whose choice of antibiotic therapy was categorized as 'other' were more concerned than other respondents about the possibility of antibiotic resistance (Table 6).

Case 3 - 45-year-old woman with no comorbidity and severe clinical presentation: For case $3,43.2 \%$ of respondents chose a third generation cephalosporin in combination with a macrolide; $18.4 \%$ chose a second generation cephalosporin with a macrolide; $12.6 \%$ chose triple therapy of a third generation cephalosporin, a macrolide and another drug; and $25.2 \%$ of respondents chose an antibiotic therapy that did not fall into any particular class. Respondent age and province of practice correlated significantly with therapeutic category for case 3 (Table 7). Respondents who chose triple therapy of third generation cephalosporin, macrolide and other tended to be younger than other respondents. Region of practice also correlated significantly with therapeutic category. When individual regions were paired with one another, significant differences were found between respondents from western provinces versus Quebec $(\mathrm{P}=0.04)$ and between Ontario versus Quebec $(\mathrm{P}=0.005)$. Most striking, while $32.4 \%$ of respondents from Ontario chose combination therapy of a second generation cephalosporin with a macrolide, only $3.3 \%$ of respondents from Quebec did so. Almost all the respondents from Quebec chose either combination therapy of a third generation cephalosporin with a macrolide (48.3\%) or a therapy categorized as 'other' (41.4\%). Confounding bias was ruled out by performing a Kruskall-Wallis one-way ANOVA, which found no interaction between age and region of practice $(\mathrm{P}=0.83)$; age and region of practice had distinct effects on choice of antibiotic. No significant correlation could be found between therapeutic category and years of infectious disease experience or location of infectious disease training.

For the closed-ended questionnaires, two-way ANOVA found no interaction significance between therapeutic class of antibiotic chosen and the weights assigned to the Likert scales $(P=0.2009)$. Qualitative analysis of the open-ended questionnaires found little differences in the rationale themes of respondents who chose different therapeutic categories of antibiotic treatment (Table 8). Most respondents justified their choice of antibiotics by stating that they wished to provide coverage for various Gram-positive and 'atypical' organisms (for example, Legionella pneumophilia). However, respondents whose choice of antibiotic therapy was defined as other were distinguished by their greater concern for providing coverage for various Gram-negative organisms, such as Klebsiella pneumoniae and Pseudomonas aeruginosa.

\section{DISCUSSION}

One aim of this study was to explore the prescribing practices of Canadian infectious disease specialists when they treat cases of CAP without culture and sensitivity information (that is, when treatment must be empirical). The study also attempted, using both quantitative and qualitative techniques, 
to understand the issues that influence the choice of antibiotic. The extremely high response rate to our questionnaires (77\%) suggests that the survey results are an accurate representation of the population under study. Whether these results reflect the real world prescribing practices of these physicians is less certain because the survey was based on questionnaires that incorporated written cases. Written cases have the disadvantage of being decontextualized and, by necessity, account for fewer clinical variables than real life cases typically involve. Unlike a chart audit, however, written cases are more economical, less time-consuming and, most important, allow for a high degree of standardization (23). However, even in this study, the three case scenarios contained different amounts of information that may have influenced the conclusions of the respondents.

The population studied in this survey is both fairly homogenous and very familiar with empirical antibiotic treatment of pneumonia. Despite this, considerable differences of opinion in choice of antibiotic and clinical judgment were observed. Indeed, some of the rationale themes identified in the open-ended questionnaires are contradictory. It is interesting to compare the prescribing preferences of the survey respondents with what would have been recommended by the Canadian Community-Acquired Pneumonia Consensus Conference Group because these guidelines would have been known to all the survey respondents. For case 1 , in which the patient was under age 65 years, previously well, had a nonsevere clinical presentation and no comorbid illness, the initial treatment recommended by Consensus Group guidelines is a macrolide. A macrolide was also the first choice of the majority $(74.7 \%)$ of survey respondents. For case 2 , in which the patient was over age 65 years, had a nonsevere clinical presentation and a likely comorbid illness, the Consensus Group guidelines recommend a second generation cephalosporin as first-line treatment. However, a second generation cephalosporin was the first choice of only $25.2 \%$ of survey respondents; most respondents (40.8\%) chose either penicillin, ampicillin or amoxicillin. Finally, for case 3, in which a previously well 45-year-old woman developed a life-threatening case of CAP, the Consensus Group guidelines recommend starting with a second or third generation cephalosporin $+/-$ a macrolide $+/$ - rifampin. This recommendation was chosen by $71.8 \%$ of respondents. Consensus Group-recommended antibiotics were chosen for all three of the cases by $15.5 \%$ of the survey respondents.

For the most part, variation in antibiotic choice did not correlate with physician characteristics; a significant correlation (with physician age and with location of practice) was found for case 3 only. One explanation is that, due to limited sample size, only case 3 had a sufficient degree of variance to allow for significance. Consensus among survey respondents regarding choice of antibiotics decreased as the complexity of the cases increased, and as the variance in antibiotic choice increased, P values decreased accordingly. A lack of significant correlation can also be attributed to the choice of method of data analysis. A number of survey respondents, particularly those who received the open-ended questionnaires, were apparently uncomfortable selecting only one antibiotic therapy and opted instead to list a number of therapeutic options that they considered equally appropriate. To simplify later analysis, these 'either/or' answers were categorized as 'other', but, as a consequence, the variance in antibiotic choice was somewhat skewed. For example, of the 12 respondents whose choice of antibiotic therapy for case 1 was categorized as 'other', seven had listed two or three alternate choices of which 'macrolide' was one. Similarly, six answered 'either penicillin or a second generation cephalosporin' as their choice of therapy for case 2 , a response that was coded as 'other'.

That being said, Canadian infectious disease specialists are apparently not an exception to the frequently observed phenomenon of younger physicians preferring newer drugs. In case 2 , this meant a slight preference for second generation cephalosporins over penicillins, while in case 3 it meant opting for a third generation over a second generation cephalosporin. That respondents from Ontario and Quebec did not differ significantly in their choice of antibiotics for either cases 1 or 2 , but did dramatically for case 3 , is also noteworthy.

To explore the decision-making process, this study employed both quantitative and qualitative research techniques $(23,25,26)$. Each method has its advantages, and the two can be complementary. The strengths of quantitative analysis are a high degree of objectivity and reproducibility, and the fact that the data generated are amenable to statistical analysis (23). For the closed-ended questionnaires, the analysis sought to determine whether there was interaction between therapeutic category and the corrected weights assigned to the Likert scales. A significant degree of interaction was taken to mean that respondents were interpreting the case's clinical cues differently.

Qualitative research, previously used most extensively in the social sciences, is finding growing popularity in biomedical research as a means of providing a preliminary foundation of information for topics about which very little is known, and in cases where the population being studied is small $(25,26)$. While qualitative research is more time-consuming and vulnerable to subjective variation than quantitative research, it is able to generate a wealth of information from which hypotheses can be generated and tested by subsequent studies (24).

In this study, qualitative analysis of the open-ended questionnaires revealed, within each case, a number of issues upon which respondents were basing their decisions. For case 1 , the principal issue was whether the patient had a 'typical' or 'atypical' type of pneumonia. While a bacterial or pneumococcal infection would be more likely to produce the lobar consolidation seen on x-ray, the patient's age and medical history are more suggestive of a mycoplasmal infection. A macrolide, while better for an atypical infection, would provide sufficient coverage for pneumococci as well, unless the patient was seriously ill. Thus, a second issue that arose was the patient's severity of illness. Although the patient's symptoms and clinical findings, as described in the case, did not suggest a serious illness, the fact that he was admitted to the hospital provoked more aggressive prescribing by a number of 
respondents, many of whom chose a combination therapy of a macrolide and another antibiotic (usually a beta-lactam). Although analysis of the closed-ended questionnaires found no significant interaction for case 1 , it should be noted that the two most heavily weighted clinical factors were 'patient immunocompetent' and 'patient seriously ill'.

For the second case, quantitative analysis of the closedended questionnaires did find near significant interaction between therapeutic category and corrected Likert scale weights, with respondents who chose penicillin placing strong emphasis on the Gram stain results to justify their choice of antibiotic. This finding is complemented by the results obtained from the open-ended questionnaires. Qualitative analysis suggested that, for this case, the main decision point was whether the patient had a pneumococcal or a Gram-negative infection. While the patient's symptoms and the results of the Gram stain point towards an infection by Streptococcus pneumoniae, the patient's age and long smoking history call his immunocompetence into question, and raise the possibility of an infection by a pathogen such as $H$ influenzae. Accordingly, respondents who chose a penicillin for case 2 were fairly confident of a pneumococcal infection, while respondents who chose a second generation cephalosporin were less likely to rule out a $H$ influenzae infection. Respondents who did not choose either of these antibiotic classes were distinguished by their concern with the possibility of antibiotic resistance.

For case 3, quantitative analysis found no significant interaction between therapeutic category and the corrected Likert scale weights, and analysis of the open-ended questionnaires was unable to provide much additional information. Regardless of the combination of antibiotics selected, respondents to the open-ended questionnaire stated that they were seeking broad coverage for a variety of Gram-positive, 'atypical' and Gram-negative pathogens, most commonly $S$ pneumoniae, Staphylococcus aureus, Legionella pneumophila and Klebsiella pneumonia. A number of respondents also wanted to provide coverage for $H$ influenzae. There was some disagreement among respondents about whether coverage for $P$ aeuruginosa was warranted, and only a few respondents sought to provide coverage for anaerobic organisms. This general desire for nonspecific broad coverage was justified most often by reference to the severity of the patient's illness, with infrequent mention of the history of present illness or chest x-ray results. Perhaps the only issue that differentiated respondents by therapeutic category was the slightly greater confidence in a Gram-negative infection among respondents whose antibiotic choice was categorized as 'other'.

Several decades of research on how physicians choose drugs has led to the development of the 'expectancy-value model' (27). According to this model, it is hypothesized that physicians decide what to prescribe by considering a list of possible outcomes that could result from each choice, weighing the desirability of each outcome, estimating each outcome's probability and then selecting the drug that has the best overall predicted result. This model was originally developed by Segal and Hepler (27), and was based in part on a study by Hepler et al (22) of physicians who empirically pre- scribed antibiotics. In this latter study, nine rationale themes for choice of a particular antibiotic agent were identified following a series of physician interviews. Six of these rationale themes involved 'instrumentality beliefs' about the relationship of the drug choice and a particular outcome, a conclusion later used to support the argument that drug choice was more of a cognitive than a habitual process.

While the expectancy-value model has proved useful for predicting drug choice for some disease states, it appears to be of little use for others (28). Critics have also found fault with the model's cognitivist assumptions - as Denig et al (29) have remarked, "physicians do not 'grow' complete decision trees in their heads for each individual patient". It has been argued that in some cases, particularly when there are many variables to consider, physicians follow more simplified algorithms (30) or even choose drugs on a behaviourist, 'pattern-recognition' basis (31).

The results of our study do not clearly support either cognitivist or behaviourist models of drug choice. Most of the rationale themes identified in this survey are instrumentalities, a finding that echoes similar research conducted by Hepler et al (22). It can also be noted that for cases 1 and 2, different antibiotic choices did not correlate well with physician characteristics but did seem to be based on different types of clinical reasoning. Both these observations support the cognitivist model. On the other hand, for case 3, the choice of antibiotic class did not appear to be based as much on differing styles of clinical reasoning as it did on the respondent's age and province of practice. Thus, at least for case 3, drug choice appears to have been related to habit and local custom, as would be predicted by a behaviourist model of drug selection.

\section{CONCLUSIONS}

Although few firm conclusions can be drawn from this survey, the results are suggestive and may prove useful in the design of future studies. One improvement would be to include nonspecialists as well as specialists in the study. A test of factual knowledge such as questions that related specifically to content of CAP pneumonia guidelines may have allowed us to correlate choice of antibiotic with the knowledge base of the respondent. In other words, do we follow expert opinion-based guidelines or do other factors influence our decision making as our data suggest?

ACKNOWLEDGEMENTS: Funding was provided by a 1996-97 PMAC Health Research Foundation Research Studentship in Medicine.

\section{REFERENCES}

1. Marrie TJ. Community-acquired pneumonia. Clin Infect Dis 1994;18:501-3.

2. Marrie TJ. New aspects of old pathogens of pneumonia. Med Clin North Am 1994;78:987-95.

3. Sue DY. Community-acquired pneumonia in adults. West J Med 1994;161:383-9.

4. Grasela TH Jr, Schentag JJ, Boekenoogen SJ, Crist KD, Lowes WL, Lum BL. A clinical pharmacy-oriented drug surveillance network: results of a nationwide antibiotic utilization review of bacterial pneumonia - 1987. DICP 1989;23:162-70.

5. Hedlund J. Community-acquired pneumonia requiring 
hospitalisation. Factors of importance for the short- and long term prognosis. Scand J Infect Dis Suppl 1995;97:1-60.

6. Marrie TJ, Durant H, Yates L. Community-acquired pneumonia requiring hospitalization: 5-year prospective study. Rev Infect Dis 1989;11:586-99.

7. Ostergaard L, Andersen PL. Etiology of community-acquired pneumonia. Evaluation by transtracheal aspiration, blood culture, or serology. Chest 1993;104:1400-7.

8. Niederman MS. Empirical therapy of community-acquired pneumonia. Semin Respir Infect 1994;9:192-8.

9. Huchon GJ, Gialdronia Grassi P, Leophonte P, et al. Initial antibiotic therapy for lower respiratory tract infections in the community: a European survey. Eur Respir J 1996;9:1590-5.

10. Örtqvist A. Antibiotic treatment of community-acquired pneumonia in clinical practice: a European perspective. J Antimicrob Chemother 1995;35:205-12.

11. Woodhead M. Empirical antibiotic therapy and lower respiratory tract infections: European guidelines and current practices. Monaldi Arch Chest Dis 1995;50:472-6.

12. Grasela TH Jr, Welage LS, Walawander CA, et al. A nationwide survey of antibiotic prescribing patterns and clinical outcomes in patients with bacterial pneumonia. DICP 1990;24:1220-5.

13. Kappstein I, Daschner FD. Antibiotic usage in community-acquired pneumonia: results of a survey in 288 departments of internal medicine in German hospitals. Infection 1991;19:301-4.

14. Taylor EL, Marrie TJ, Fine MJ. Observations from a multicentre study in the use of the sputum specimen in patients hospitalized with community-acquired pneumonia. Can J Infect Dis 1999;10:39-46.

15. Hueston WJ, Schiaffino MA. Antibiotic choice and patient outcomes in community-acquired pneumonia. J Am Board Fam Pract 1994;7:95-9.

16. Guglielmo L, Leone R, Moretti U, Conforti A, Spolaor A, Velo G. Antibiotic prescribing patterns in Italian hospital inpatients with pneumonia, chronic obstructive pulmonary disease, and urinary tract infections. Ann Pharmacother 1993;27:18-22.

17. The aetiology, management and outcome of severe community-acquired pneumonia on the intensive care unit. The British Thoracic Society Research Committee and The Public Health Laboratory Service. Respir Med 1992;86:7-13.

18. Gialdroni Grassi G, Bianchi L. Guidelines for the management of community-acquired pneumonia in adults. Italian Society of Pneumology. Italian Society of Respiratory Medicine. Italian
Society of Chemotherapy. Monaldi Arch Chest Dis 1995;50:21-7.

19. Mandell LA, Niderman MS. The Canadian Community Acquired Pneumonia Consensus Conference Group. Antimicrobial treatment of community acquired pneumonia in adults: a conference report. Can J Infect Dis 1992;86:503-5.

20. Niderman MS, Bass JB Jr, Campbell GD, et al. Guidelines for the initial management of adults with community-acquired pneumonia: Diagnosis, assessment of severity, and initial antimicrobial therapy. American Thoracic Society. Medical Section of the American Lung Association. Am Rev Respir Dis 1993;148:1418-26.

21. Mandell LA, Niderman M. Antimicrobial treatment of community acquired pneumonia: A conference report. Can J Infect Dis 1993:4:25-8.

22. Hepler CD, Clyne KE, Donata ST. Rationales expressed by empiric antibiotic prescribers. Am J Hosp Pharm 1982;39:1647-55.

23. Miles MB, Huberman AM. Qualitative Data Analysis: An Expanded Sourcebook, 2nd edn. London: Sage Publications, 1994.

24. Leedom JM. Pneumonia. Patient profiles, choice of empiric therapy, and the place of third-generation cephalosporins. Diagn Microbiol Infect Dis 1992;15:57-65.

25. Jones TV, Gerrity MS, Earp J. Written case simulations: do they predict physicians' behavior? J Clin Epidemiol 1990;43:805-15.

26. Bradley CP. Decision-making and prescribing patterns a literature review. Fam Pract 1991;8:276-87.

27. Segal R, Hepler CD. Prescribers' beliefs and values as predictors of drug choices. Am J Hosp Pharm 1982;39:1891-7.

28. Denig P, Haaijer-Ruskamp FM, Zusling DH. How physicians choose drugs. Soc Sci Med 1988;27:1381-6.

29. Denig P, Haaijer-Ruskamp FM, Wesseling H, Versluis A. Towards understanding treatment preferences of hospital physicians. Soc Sci Med 1993;36;915-24.

30. Chinburapa V, Larson LN, Brucks M, Draugalis J, Bootman JL, Puto CP. Physician prescribing decisions: the effects of situational involvement and task complexity on information acquisition and decision-making. Soc Sci Med 1993;36:1473-82.

31. Bergus GR, Hamm RH. Clinical practice. How physicians make medical decisions and why medical decision making can help. Prim Care 1995;22:167-80. 


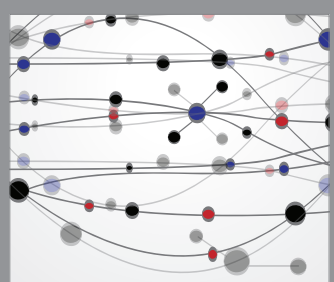

The Scientific World Journal
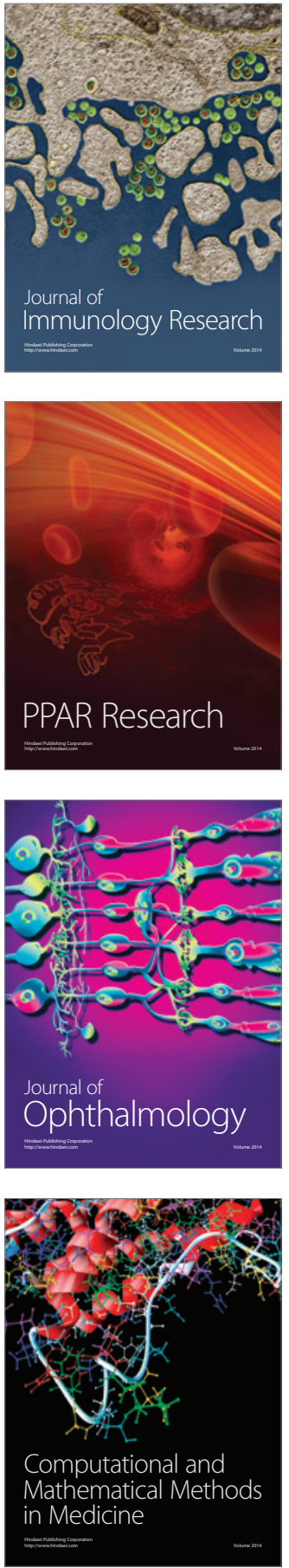

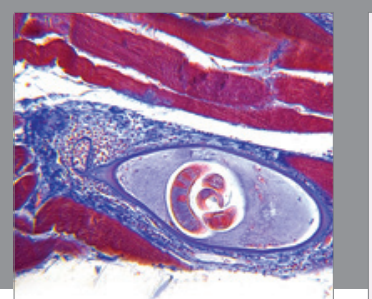

Gastroenterology Research and Practice

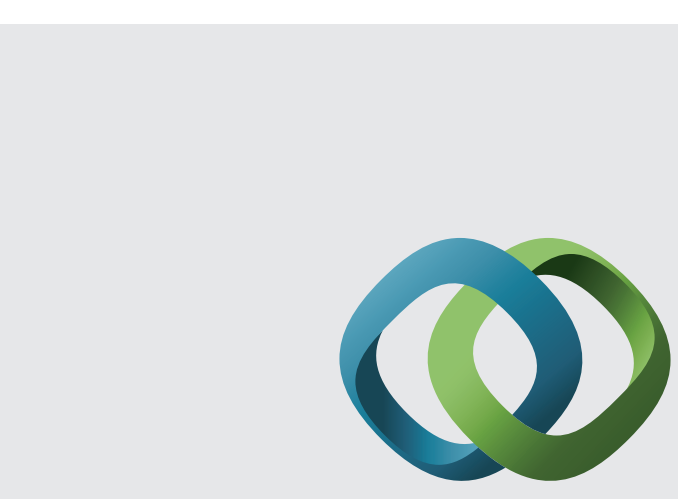

\section{Hindawi}

Submit your manuscripts at

http://www.hindawi.com
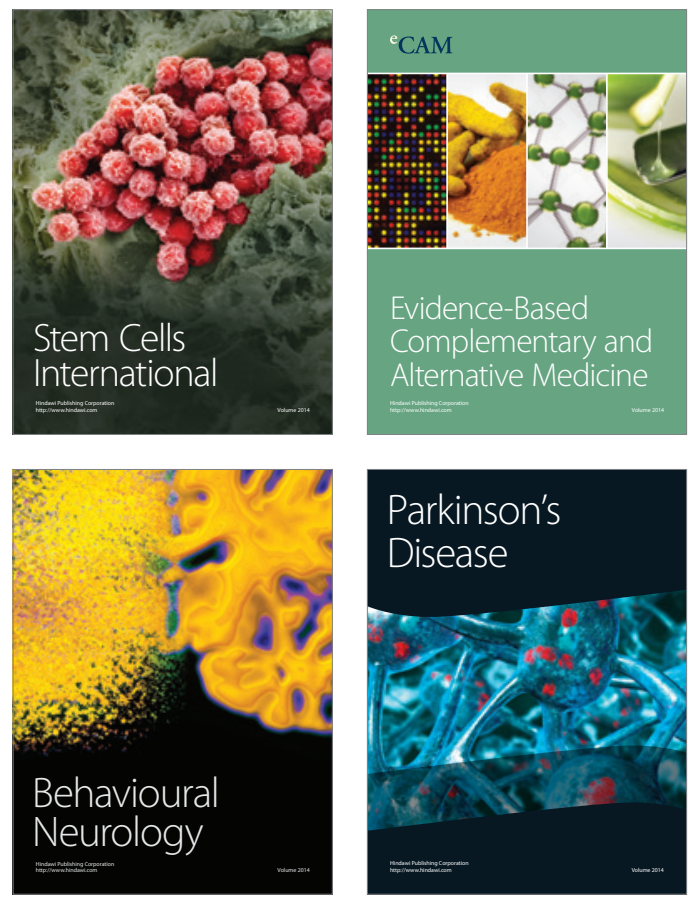
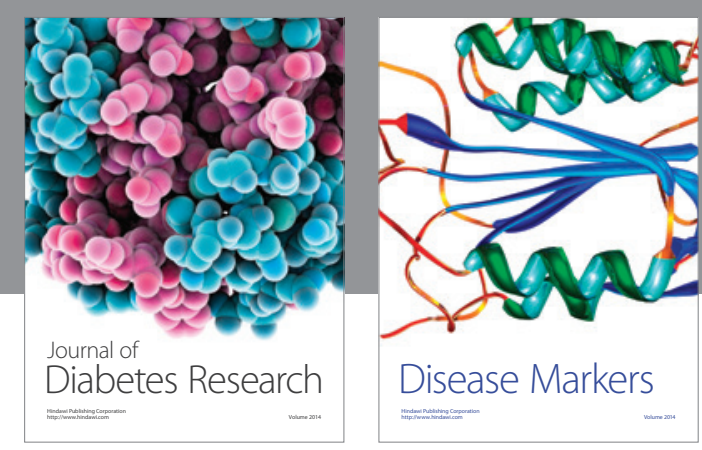

Disease Markers
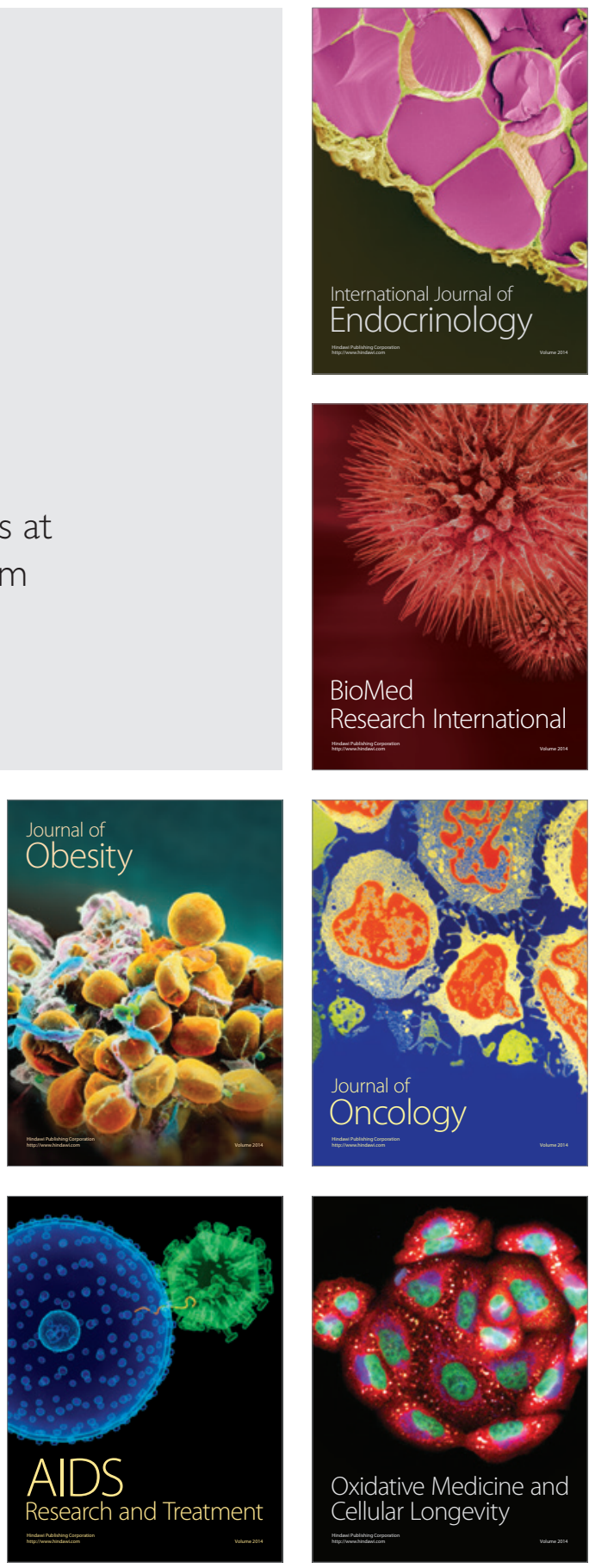